\title{
DIFFUSION OF REDOX ACTIVE MOLECULES IN DEEP EUTECTIC SOLVENTS.
}

Stéphanie Fryars, Emmanuelle Limanton, Fabienne Gauffre, Ludovic Paquin, Corinne Lagrost, Philippe Hapiot*

Université de Rennes 1, Institut des Sciences Chimiques de Rennes (Equipes MaCSE and CORINT), CNRS, UMR 6226, Campus de Beaulieu, Bat 10C, 35042 Rennes Cedex, France

In memorial of Prof. Rodger Parsons.

\begin{abstract}
Classical electrochemical approaches were evaluated for investigating the basic properties of deep eutectic solvents (DES) with a special focus on the mass transport phenomena and diffusion of charged species in DES. Three classical DES were considered: Reline, Ethaline and cholinechloride-lactic acid mixture. Cyclic voltammetries of the ferrocene oxidation and of the ferricyanide reduction, respectively with charge 0 and -3 , exhibit well-defined responses in these media. For all considered DES and redox molecules, diffusion processes govern the masstransport of the redox molecules from the solution to the electrode. Derived diffusion coefficients were extracted and found to present some inconstancies with the classical StokesEinstein law for homogeneous media. The diffusion coefficients were found to be almost unaffected by the charge present on the diffusing molecules contrarily to observations made for ionic liquids.
\end{abstract}

\section{Keywords:}

Deep Eutectic Solvents. Redox Probes. Cyclic Voltammetry. Diffusion Coefficients.

\section{Introduction}

Deep eutectic solvents (DESs) represent a novel class of solvents that has already been proposed for many applications in chemistry including uses in electrochemistry.[1,2,3,4,5] Historically, researches about DESs are related to the Ionic liquids (ILs) that are organic salts with a low melting point $\left(<100^{\circ} \mathrm{C}\right)$ combining an organic cation with an organic or inorganic anion.[6,7,8,9,10] DESs and ILs have both attractive physical properties: they are non-volatile, non-flammable and their solvent properties could be tailored by designed functions, therefore the considered applications of DESs or ionic liquids are often similar. They are well-adapted for numerous applications ranging from catalysis, biocatalysis, electrochemistry for energy storage to extraction processes.[6-11,12] In a pioneering work, A.P. Abbott et al. have reported the first associations between choline chloride and natural compounds such as urea in 2003.[3] 
Associations in DESs could involve different interactions such as hydrogen bonds between a hydrogen-bonding donor (HBD) and a hydrogen-bonding acceptor (HBA). The choice of the components to form a DES is thus immense as DES could associate one to several compounds in different proportions.[1-5,13,14,15, 16,17]]

Electrochemistry studies and more particularly cyclic voltammetry have largely been used to characterize the basic properties of neoteric solvents as ionic liquids $[7,8]$ and are well adapted to studies in DESs. However, a direct extrapolation of properties in DESs from those determined in ILs is not straightforward because molecular interactions in the DESs have different origin and diversity. Although recent literature has clearly proved the potential interests of DESs, fundamental investigations in DES using electrochemistry remain limited. LeSuer et al. have reported in 2007 about the ferrocene oxidation in two choline chloride based DESs: ChCltrifluoroacetamide and $\mathrm{ChCl}$-malonic acid showing the interest of the electrochemical approaches based on cyclic voltammetry and SECM.[13] More recently, the electrochemistry of ferrocene and cobaltocene were investigated using cyclic voltammetry in $\mathrm{ChCl}$ based DESs and their diffusion coefficients were derived in these media.[18,19,20] The electrochemical behavior of metal couples such as $\mathrm{Fe}^{3+} / \mathrm{Fe}^{2+}\left[[21,22,23]\right.$ or $\mathrm{Cu}^{2+} / \mathrm{Cu}^{+}[24]$ were also examined in DES. They were found to form complexes in $\mathrm{ChCl}$-based DESs making their use as "inert" redox probe more complicated because the diffusive species could be totally different when changing the DES.

Based on NMR investigations, self-diffusion was examined in four ChCl-based DESs and diffusion coefficients were measured.[25] From comparison of experiments with viscosity data and models, it was concluded that the diffusion mechanism is similar to that in pure ionic liquids, which acts via a hopping mechanism or hole diffusion rather than the random walk model used to describe diffusion in conventional homogeneous liquids.[25]

In this context, we have performed a series of experiments with a special focus on the diffusion processes involved in DESs. A central question concerns the effect of the charge carried by the redox probe and the inner sphere character of the electron transfer of the redox probe on the mass transport. One could expect that a charged molecule will present a specific association with the cation/anion of the DES providing information about its structure if any.[7,8] We have used the cyclic voltammetry on a millimetric electrode and have selected the reduction of ferricyanide by comparison with the oxidation of ferrocene in 3 different DESs prepared from mixture of choline chloride $(\mathrm{ChCl})$ and different hydrogen bond donors (HBDs) (See Table 1). These two redox molecules were chosen for their chemical stability, the specificity of their electron transfers and the charges present on the molecules. The ferrocene/ferrocenium couple is an outsphere system that is relatively insensitive to solvation 
change and its oxidation involves the passage from a charge 0 to +1 . In contrast, the reduction of ferricyanide $\left[\mathrm{Fe}(\mathrm{CN})_{6}\right]^{3-}$ to ferrocyanide $\left[\mathrm{Fe}(\mathrm{CN})_{6}\right]^{4-}$ involves an electron transfer with a strong inner sphere character for a molecule that is negatively charged (passage from -3 to -4 upon reduction). We present here our first results using cyclic voltammetry and preliminary conclusions about the specificity of the mass transport/diffusion properties in DES notably for neutral and charged redox probes.

Table 1. DES used in this work.

\begin{tabular}{|c|c|c|c|}
\hline DES & Organic Salt & Hydrogen Donor (HBD) & Molar Ratio \\
\hline Ethaliı & & & $1: 2$ \\
\hline Reline & & & $1: 2$ \\
\hline $\mathrm{ChCl}-$ & & & $1: 1$ \\
\hline
\end{tabular}

\section{Experimental.}

All electrochemical measurements were performed with an Autolab PGSTAT 302N (Metrohm) using a conventional 3-electrode setup.[7,8] The reference electrode was a quasireference electrode made with a Pt wire. The counter-electrode was a large Pt wire and the working electrode a 1-millimeter diameter Pt disk electrode. Potentials are reported versus the Pt quasi-reference electrode scale for an easier comparison of original experiments.

Maximum faradaic peak current, $I_{p}$ were measured after correction of the baseline that was estimated under the faradaic peak by a linear extrapolation of the background current determined at the beginning of the voltammogram. D values were derived assuming a reversible electron transfer.[26]

Ferrocene and potassium ferricyanide were of the highest available purity grade from commercial source (Aldrich) and used without further purification. Solutions of ferrocene in the DESs were prepared by heating the DES with the solute with a gradual increase of the temperature up to $60^{\circ} \mathrm{C}$ in an ultrasonic bath. We found that concentrations around $5 \times 10^{-3} \mathrm{~mol}$ $\mathrm{L}^{-1}$ are accessible without the appearance of a precipitate when the solution was cooled down to room temperature. Such concentrations were sufficient to record currents with a good ratio between the signal and background currents and noise. 
Ethaline, Reline and choline chloride - lactic acid were prepared from commercially available compounds obtained from Aldrich according to published procedures.[27,28] Mass fraction of residual water was measured by using a coulometric Karl-Fisher titration (831KF Coulometer Metrohm and using Hydranal® Coulomat E solution from Fluka) for each sample and found in the order of 3-7 wt \% depending on the DES.

Dynamic viscosities of DES were determined for each sample and the considered temperatures using an Anton-Parr Rheometer MCR301. Experiments are performed with a plateplate setup (diameter: $75 \mathrm{~mm}$ and gap: $1 \mathrm{~mm}$ ) in a steady-shear mode. In this protocol, the shear stress and the viscosity are measured as a function of the imposed shear rate. The temperatures is controlled by a Peltier device, with a $0.1^{\circ} \mathrm{C}$ accuracy.

\section{Results and Discussion}

In this work, we use a simple electrochemical system, based on millimetric electrodes and without using electronic compensation of the ohmic drop. Cyclic voltammetries were recorded at different scan rates and at increasing temperature to get a characterization of the mass transport processes in these DESs. DESs were used as prepared to be as close as possible to the solvents used in practical applications. They contain considerable amount of water (3 to $7 \mathrm{wt} \%$ depending on the DES). As reported for ILs, the properties of "wet" DES has been shown to vary in a large extent from ultra-dry liquids.[29]

\subsection{Investigations in Ethaline (ChCl/ethylene glycol 1:2).}

Cyclic voltammetries of the reduction of ferricyanide and oxidation of ferrocene in Ethaline are displayed in Figure 1 at increasing scan rates from 0.02 to $0.5 \mathrm{~V} . \mathrm{s}^{-1}$ and for two temperatures $\left(20^{\circ} \mathrm{C}\right.$ and $\left.60^{\circ} \mathrm{C}\right)$. No additional supporting electrolytes were added in the solution meaning that the conductivity of the DES relies solely on its intrinsic conducting properties. It is remarkable that both ferrocene oxidation and ferricyanide reduction display well-defined voltamograms with the classical shape expected for a reversible redox couple.[26] Variations of the faradaic peak currents intensities corrected from the baseline, $\mathrm{I}_{\mathrm{p}}$, were measured as function of the scan rate $\mathrm{v}$, (See Figure 2). We used the definition of the peak current Ip for a reversible voltammogram $\left(\mathrm{I}_{\mathrm{p}}=\right.$ $0.446 \mathrm{FSC}^{\circ}(\mathrm{Fv} / \mathrm{RT})^{1 / 2}$ to derive the value of the diffusion coefficient; where $\mathrm{S}$ is the electrode area, $\mathrm{C}^{\circ}$ the initial concentration of ferrocene or ferricyanide, $\mathrm{T}$ the temperature and $\mathrm{F}$ and $\mathrm{R}$ the Faraday and molar gas constants).[26] For both ferricyanide reduction and ferrocene oxidation,

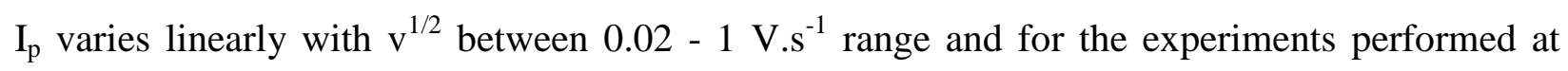
$20^{\circ} \mathrm{C}$ and $60^{\circ} \mathrm{C}$ (see Figure 2). Such linear variations mean that the mass-transport of the redox species from the solution bulk to the electrode surface is controlled by their diffusion. $I_{p}$ 
increases when increasing the temperature as expected for a lower viscosity of the DES in agreement with reported previous studies.[18,19,20]
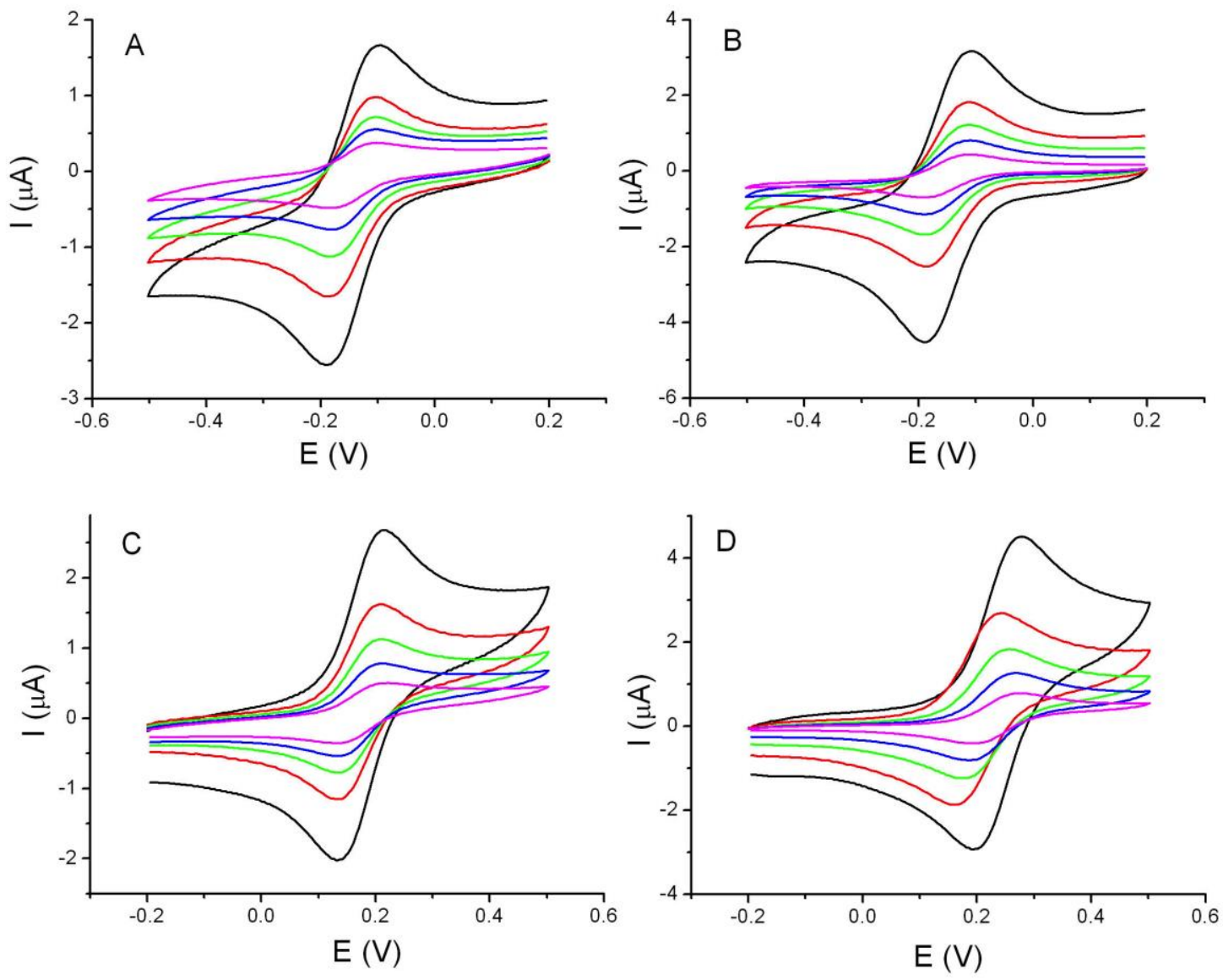

Fig. 1. Cyclic voltammetry of the reduction of ferricyanide $(A, B)$ and oxidation of ferrocene $(C, D) 5 \times 10^{-3}$ mol $\mathrm{L}^{-1}$ in Ethaline for different scan rates $\left(20,50,100,200,500 \mathrm{mV} \mathrm{s}^{-1}\right)$ at $20^{\circ} \mathrm{C}(\mathrm{A}, \mathrm{C})$ and $60^{\circ} \mathrm{C}(\mathrm{C}, \mathrm{D})$.

From the linear slopes of the $\mathrm{I}_{\mathrm{p}} / \mathrm{v}^{1 / 2}$ variations, we derived the values of the diffusion coefficients, D, of ferricyanide and ferrocene in the DES (See Table 2). D values around $10^{-7} \mathrm{~cm}^{2}$ $\mathrm{s}^{-1}$ are obtained at $20^{\circ} \mathrm{C}$ and in the $3-4 \times 10^{-7}$ range at $60^{\circ} \mathrm{C}$ which correspond to an increase of the diffusion coefficient by a factor 3.5-3.7 between 20 and $60^{\circ} \mathrm{C}$. It is remarkable that the D values for ferricyanide and ferrocene are similar despite the large differences of charges of the two molecules ( -3 for ferricyanide and 0 for ferrocene) and display similar increases with the temperature.

Viscosity and amount of water present in the DES (measured on the same sample) are also reported in Table 2. By comparison with literature, derived diffusion coefficient of ferrocene in Ethaline are 2-3 times larger than those previously reported in the same DES at $25^{\circ} \mathrm{C}$.[18] These difference falls in line with a lower measured viscosity of our DES; 44 mPas s versus 66 mPas s [18] that could be ascribed to a higher quantity of water in the DES. As done previously (see for example ref 18, 29, 30 and references therein), comparison between $\mathrm{D}$ values and the 
experimental viscosities brings valuable information about the diffusion mechanism. For an ideal liquid, the classical Stokes-Einstein relation predicts that $D$ varies as $T / \eta$ (where $\eta$ is the dynamic viscosity of the DES). The validity of the law could be evaluated by simply considering the correlation coefficient $\varepsilon=T /(\eta D)$ that must remain constant with the temperature.[28,30] In ultra-dry ILs and DES, inconstancies versus the Stokes-Einstein law were reported for the diffusion of ferrocene. They were explained by considering the inhomogeneity of such media versus a classical solvent.[25,30] We did not evidence such a discrepancy with our measurements in Ethaline (See Table 2), $\varepsilon$ varies by around $25 \%$ that is a reasonable agreement with the Stokes-Einstein law considering the uncertainties on the viscosity measurements and diffusion coefficients.
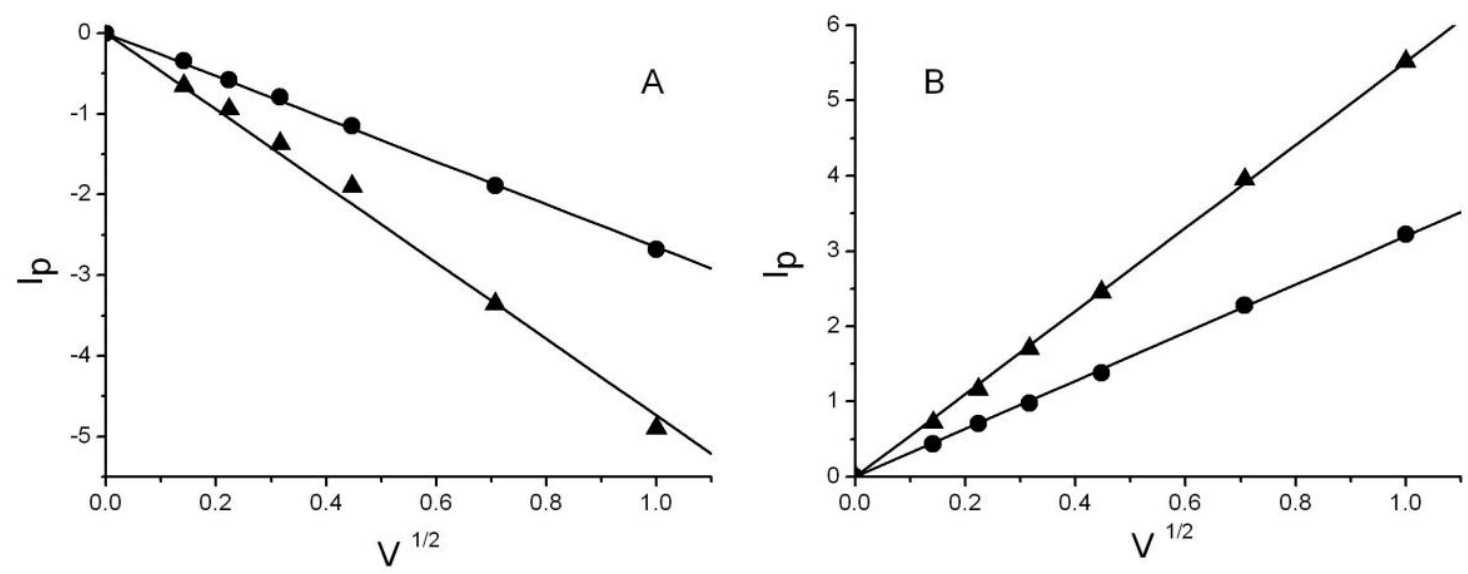

Fig. 2. Variations of the peak current Ip with the square root of the scan rate $\left(v^{1 / 2}\right)$ for the reduction of the ferricyanide (A) and oxidation of the ferrocene (B) $\left(5 \times 10^{-3} \mathrm{~mol} \mathrm{~L}^{-1}\right.$ in Ethaline) at $20^{\circ} \mathrm{C}$ and $60^{\circ} \mathrm{C}$.

At this point, it is also relevant to compare our "electrochemical" data with the self-diffusion coefficients measured by NMR in the same DES and temperature.[25] D value of $4.8 \times 10^{-7} \mathrm{~cm}^{2}$ $\mathrm{s}^{-1}$ was reported for the self-diffusion of choline cation at $60^{\circ} \mathrm{C}$ that is comparable to the $2.3 \times 10^{-}$ ${ }^{7} \mathrm{~cm}^{2} \mathrm{~s}^{-1}$ and $3.1 \times 10^{-7} \mathrm{~cm}^{2} \mathrm{~s}^{-1}$ that we derived for ferricyanide and ferrocene respectively at the same temperature in Ethaline. It is also noticeable that the electrochemical and NMR analyses are performed with different characteristic times, they are typically in the $0.2-2 \mathrm{~s}$ range in our electrochemistry experiments that is longer than the $0.05 \mathrm{~s}$ delay used in NMR measurements.[25]

\subsection{Investigations in Reline (ChCl/urea 1:2).}

Similar electrochemical studies of the reduction of ferricyanide and the oxidation of ferrocene were performed in Reline (see Figure 3) at increasing scan rates from 0.02 to $0.5 \mathrm{~V} . \mathrm{s}^{-1}$. Reline is a less adapted solvent as it presents a much higher viscosity ( $835 \mathrm{mPa} \mathrm{s})$ at $25^{\circ} \mathrm{C}$ and $231 \mathrm{mPa} \mathrm{s}$ at $60^{\circ} \mathrm{C}$ with $3 \mathrm{wt} \%$ of water) and a lower conductivity. Additionally, ferrocene was found to 
present a very low solubility at $20^{\circ} \mathrm{C}$ and an acceptable but still low solubility at $60^{\circ} \mathrm{C}$ which impedes an accurate determination of the diffusion coefficient in the same experimental conditions.
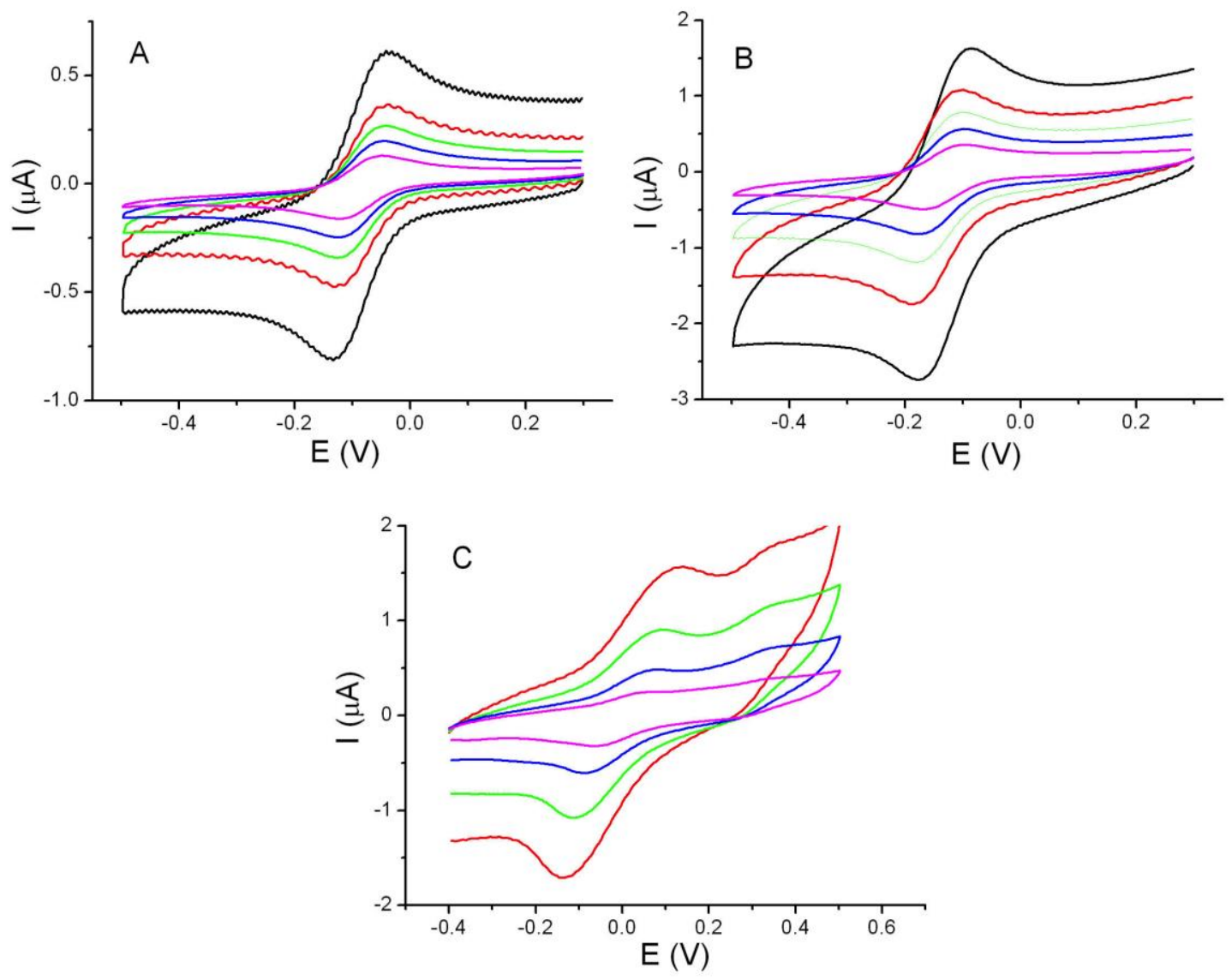

Fig. 3. Cyclic voltammetry of the reduction of ferricyanide $(A, B)$ and oxidation of ferrocene $(C) 510^{-3} \mathrm{~mol} \mathrm{~L}^{-1}$ in Reline for different scan rates $\left(20,50,100,200,500 \mathrm{mV} \mathrm{s}^{-1}\right)$ at $20^{\circ} \mathrm{C}(\mathrm{A})$ and $60^{\circ} \mathrm{C}(\mathrm{B}, \mathrm{C})$.

As seen in Figures 3A and 3B, well-defined voltamograms are obtained for ferricyanide reduction but less-defined curves with large background current for ferrocene oxidation. We could ascribe this observation to partial blockings of the electrode related to the low solubility of ferrocene that favors the deposition onto the electrode surface. At this point, only the electrochemical responses of ferricyanide reduction were analyzed in Reline.

Figure 4 shows the variation of the peak currents with the square root of the scan rate $\left(v^{1 / 2}\right)$. As for the experiments performed in Ethaline, the peak current displays a clear linear variation with the square root of the scan rate at both $20^{\circ} \mathrm{C}$ and $60^{\circ} \mathrm{C}$. From the slopes, we derived D values of $6.2 \times 10^{-9}$ and $5.4 \times 10^{-9} \mathrm{~cm}^{2} \mathrm{~s}^{-1}$ for ferricyanide in Reline. These values are much lower than those measured in Ethaline as expected from the higher viscosity of Reline. However, the correlation coefficient $\varepsilon=T /(\eta D)$ that evaluates the validity of the Stokes-Einstein law considerably varies (around a factor of 2). These results need confirmation by adding other measurements and increasing the temperature range, but on sole base of these preliminary 
experiments, it suggests that diffusion does not behave like a simple random walk like in conventional solvents.[30]

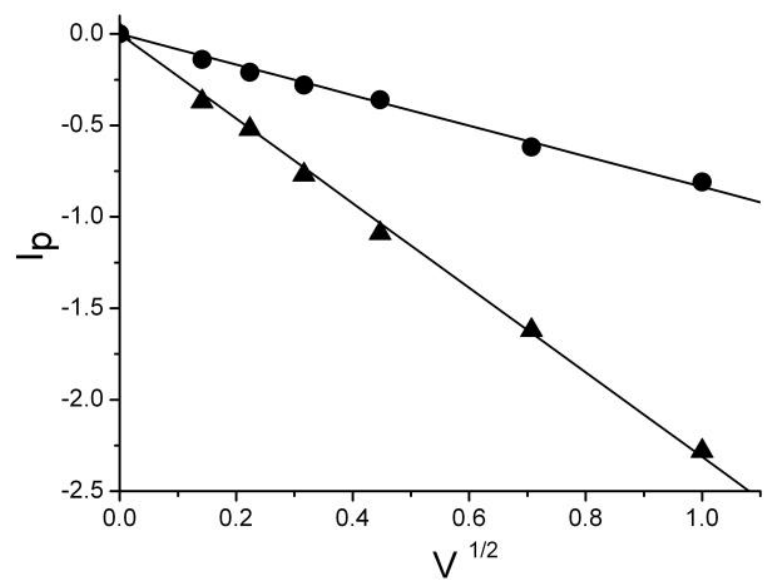

Fig. 4. Variation of the peak current Ip with the square root of the scan rate $\left(v^{1 / 2}\right)$ for the reduction of the ferricyanide $\left(5 \times 10^{-3} \mathrm{~mol} \mathrm{~L}^{-1}\right)$ in Reline) at $20^{\circ} \mathrm{C}$ and $60^{\circ} \mathrm{C}$.

\subsection{Investigations in choline-chloride/lactic acid) eutectic (ChCl-lactic acid 1:1).}

Finally, the same investigations were performed in a choline-chloride / lactic acid eutectic (1:1). As a qualitative analysis, the electrochemical signal is more defined at higher temperature especially for ferrocene oxidation (See Figure 5). Besides a possible faster electron transfer kinetics; such improvement is probably due to the concomitant decrease of the ohmic drop, a lower viscosity of the DES and a better solubility of the ferrocene in the DES at high temperature. One could notice that the peak-to-peak potential separations decrease when the temperature increases that supports a lower resistivity of the DES and/or a faster electron transfer. As obtained for the two other DESs, peak currents Ip show a linear variation with the square root of the scan rate $v^{1 / 2}$ that are indicative of a diffusion-controlled process in this DES as found in the two previous DES.[26] 

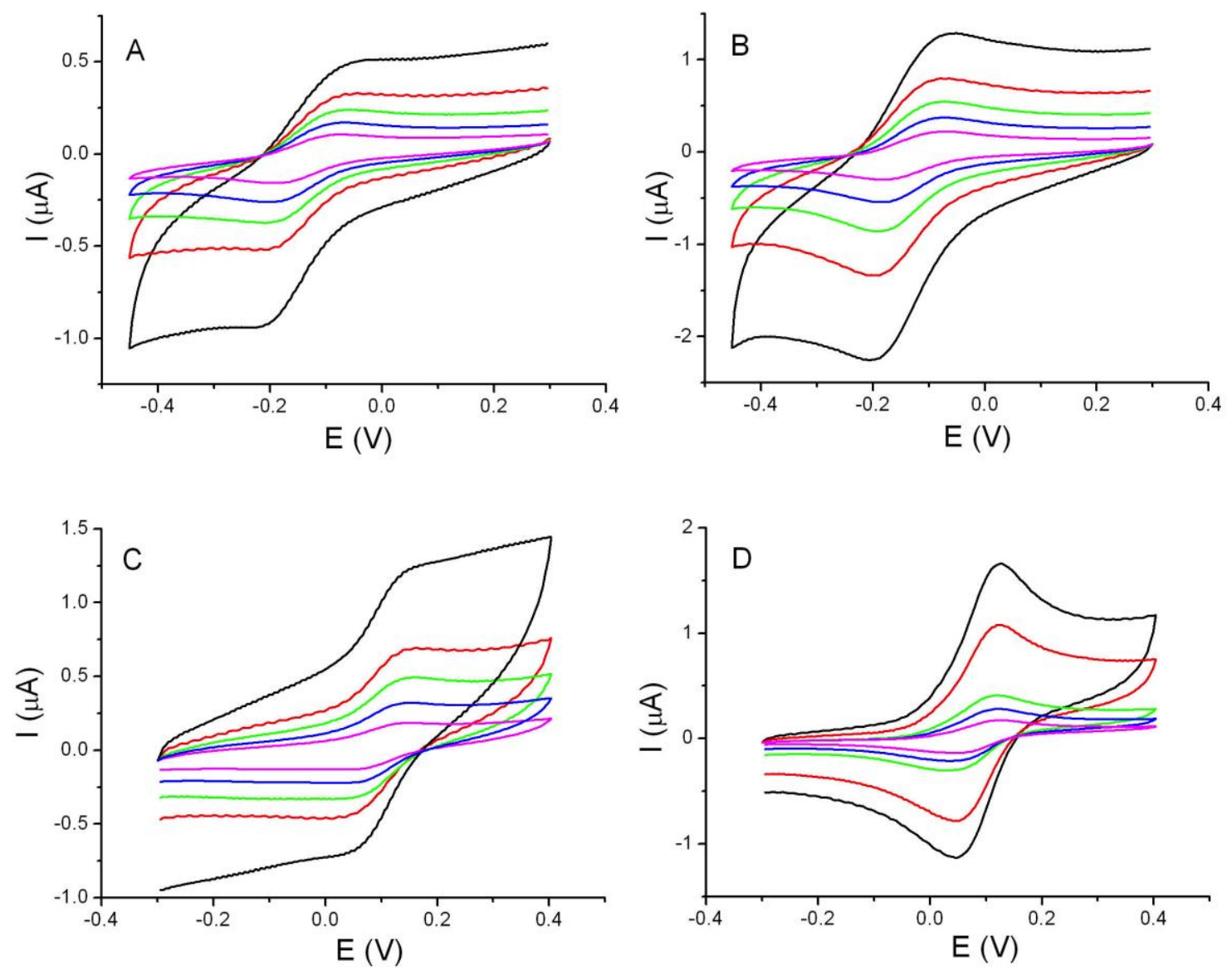

Fig. 5. Cyclic voltammetry of the reduction of ferricyanide $(A, B)$ and oxidation of ferrocene (C,D) at $5 \times 10^{-3} \mathrm{~mol} \mathrm{~L}^{-}$ ${ }^{1}$ in chloline chloride / lactic acid eutectic for different scan rates $\left(20,50,100,200,500 \mathrm{mV} \mathrm{s}^{-1}\right)$ at $20^{\circ} \mathrm{C}(\mathrm{A}, \mathrm{C})$ and $60^{\circ} \mathrm{C}(\mathrm{C}, \mathrm{D})$. Co

From the slopes, we derived the diffusion coefficients that are shown in Table 2. From the variation of $\varepsilon$ in Table 2, agreement with the Stokes Einstein variation is reasonable when the redox probe is ferricyanide.
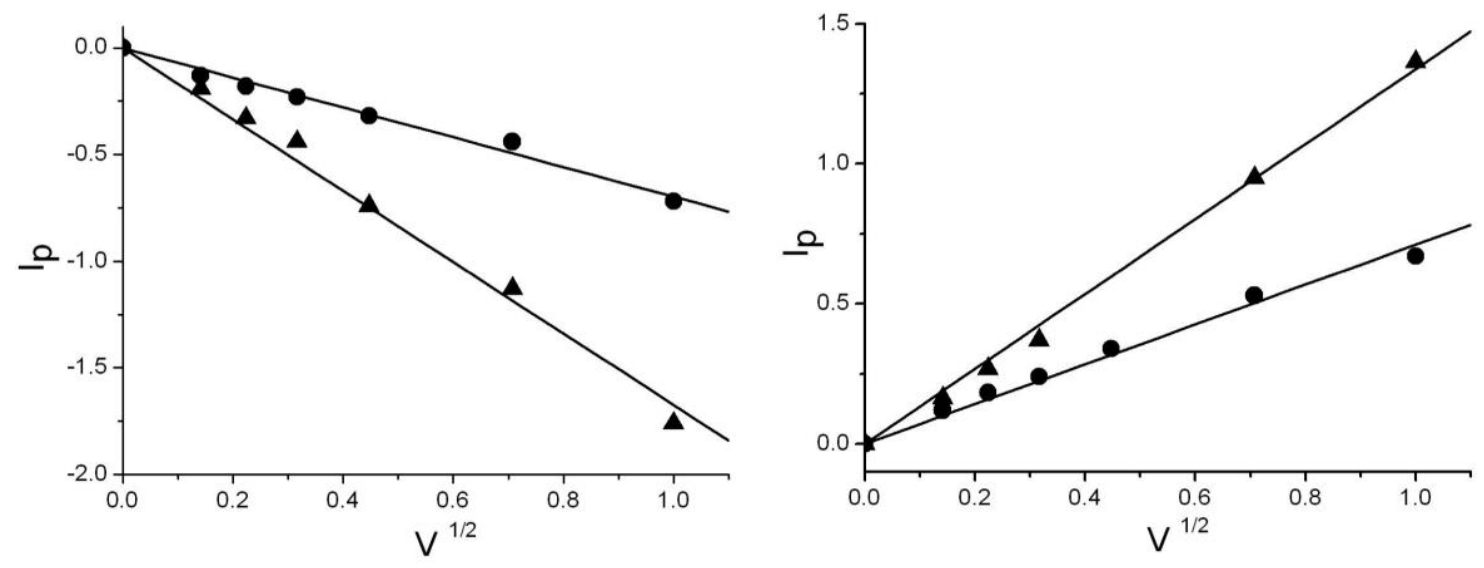

Fig. 6. Variation of the peak current Ip with the square root of the scan rate $\left(\mathrm{v}^{1 / 2}\right)$ for the reduction of the ferricyanide (A) and oxidation of the ferrocene $\left(5 \times 10^{-3} \mathrm{~mol} \mathrm{~L}^{-1}\right.$ in Choline chloride / lactic acid) at $20^{\circ} \mathrm{C}$ and $60^{\circ} \mathrm{C}$. 


\subsection{Diffusion mechanism.}

On the whole, measured values of the diffusion coefficients are in the same range than data reported in the literature especially if one consider that "wet" DESs are less viscous.[18-25] In Reline, diffusion was found to not follow the Stokes-Einstein law predicting that D should vary as $T / \eta$. On the contrary, in Ethaline that is a less viscous DES, the Stokes-Einstein seems to prevail at least in the $20-60^{\circ} \mathrm{C}$ range and both for the diffusion of ferricyanide and ferrocene. Limited or bad agreement with the Stokes-Einstein was already been reported leading to the conclusion that diffusion mechanism in DES is similar to that in the ILs [25] where a hopping mechanism or hole diffusion were proposed to explain transport inside the ILs [6-8,30]. The inhomogeneity of the media is often highlighted to explain the inconsistencies with the assumptions made in Stokes-Einstein equation.[30]

Table 2. Diffusion Coefficients measured in the DESs.

\begin{tabular}{lcccccc}
\hline Eutectic & $\begin{array}{c}\text { Viscosity } \\
(\text { mPa.s })\end{array}$ & wt\% $\mathrm{H}_{2} \mathrm{O}$ & Probe/Temp. & $\begin{array}{c}\text { Slope } \\
\left(\mu \mathrm{A} \mathrm{V}^{1 / 2} \mathrm{~s}^{1 / 2}\right)\end{array}$ & $\begin{array}{c}D \\
\left(\mathrm{~cm}^{2} \mathrm{~s}^{-1}\right)\end{array}$ & $\varepsilon=T /(\eta \mathrm{D})$ \\
\hline Ethaline & 44 & 2.9 & Ferricyanide $/ 20^{\circ} \mathrm{C}$ & -2.65 & $6.2 \times 10^{-8}$ & $0.98 \times 10^{8}$ \\
Ethaline & 18 & 2.9 & Ferricyanide $/ 60^{\circ} \mathrm{C}$ & -4.74 & $2.3 \times 10^{-7}$ & $0.80 \times 10^{8}$ \\
Ethaline & 44 & 2.9 & Ferrocene $/ 20^{\circ} \mathrm{C}$ & 3.19 & $9.0 \times 10^{-8}$ & $0.74 \times 10^{8}$ \\
Ethaline & 18 & 2.9 & Ferrocene $/ 60^{\circ} \mathrm{C}$ & 5.51 & $3.1 \times 10^{-7}$ & $0.60 \times 10^{8}$ \\
Reline & 835 & 3.2 & Ferricyanide $/ 20^{\circ} \mathrm{C}$ & -0.837 & $6.2 \times 10^{-9}$ & $0.57 \times 10^{8}$ \\
Reline & 210 & 3.2 & Ferricyanide $/ 60^{\circ} \mathrm{C}$ & -2.31 & $5.4 \times 10^{-8}$ & $0.29 \times 10^{8}$ \\
ChCl - Lactic Ac. & 447 & 6.9 & Ferricyanide $/ 20^{\circ} \mathrm{C}$ & -0.70 & $4.4 \times 10^{-9}$ & $1.49 \times 10^{8}$ \\
ChCl - Lactic Ac. & 64 & 6.9 & Ferricyanide $/ 60^{\circ} \mathrm{C}$ & -1.67 & $2.8 \times 10^{-8}$ & $1.85 \times 10^{8}$ \\
$\mathrm{ChCl}$ - Lactic Ac. & 447 & 6.9 & Ferrocene $/ 20^{\circ} \mathrm{C}^{*}$ & 0.712 & $4.5 \times 10^{-9}$ & $1.45 \times 10^{8}$ \\
$\mathrm{ChCl}$ - Lactic Ac. & 64 & 6.9 & Ferrocene $/ 60^{\circ} \mathrm{C}$ & 1.34 & $1.8 \times 10^{-8}$ & $2.89 \times 10^{8}$ \\
\hline
\end{tabular}

The most remarkable result of Table 2 is the low sensitivity of the diffusion coefficients to the charge of the diffusing molecule. Between ferrocene and ferricyanide, the variation of $\mathrm{D}$ is lower than $30 \%$ as the charge is -3 for ferricyanide and 0 ferrocene. We could also make comparisons with the self-diffusion coefficient of the choline-chloride cation $($ charge +1$)$ in Ethaline that was also reported in the same order [25]. By analogy, we could remind that the diffusion of charged molecules dissolved in ionic liquids is considerably dependent on the charge. It was shown that the diffusion coefficient in ILs depends both on the delocalization of the charge on the molecule and its size.[31] For the $\mathrm{O}_{2} / \mathrm{O}_{2}{ }^{--}$couple that is probably an extreme case, the diffusion coefficient of $\mathrm{O}_{2}$ is 40 times larger than that of $\mathrm{O}_{2}^{-{ }^{-}}$in common ILs.[32,33] However for larger molecules like nitrotoluene/nitrotoluene radical anion in common ILs, the neutral molecule still displays a considerable effect as diffusion coefficient of the radical anion is around 4 times smaller than the 
neutral one despite a delocalization of the charge in the aromatic ring.[31] This effect illustrates the strong ionic interactions between the redox charged species and the ions of the IL in combination with the occurrence of a possible hopping mechanism diffusion.[7] No such effects are visible in DES suggesting a much lower interaction between the solute and the solvent. Other studies are required to generalize these conclusions but from these sole results, it is clear that if DESs are comparable to ionic liquids, the transport mechanism is probably different.

\section{Conclusion}

Our experiments show that quantitative electrochemical studies could be performed in common DESs using simple cyclic voltammetry even when the redox probe is a highly charged molecule like ferrocyanide. In all considered DESs and both for ferrocene and ferrocyanide, diffusion was found as the major mass transport processes in agreement with literature results concerning similar DES.

The diffusion coefficients measured by electrochemistry were found in the same range as previously reported in previous electrochemistry investigations but also with the self-diffusion coefficients derived from NMR measurements despite different experimental times. If diffusion coefficients are smaller than those observed in classical solvents in agreement with a higher viscosity, they remain sufficiently large for use of DESs in most applications in electrochemistry. By comparison with reports in ILs, only small variations of the diffusion coefficients were observed when changing the charge of the molecule. Other parameters as the quantity of water also need to be considered to precise how the amount of an additional component in the DES plays a role in the observed properties.

In this regard, DESs present many similarities but also differences with ionic liquids probably because of the presence of non-ionic components in the formulation of the DES. Other detailed studies are required notably with other DES to get a better view of diffusion processes in DES as mass transport is a fundamental characteristic for most applications of such solvents.

\section{References}

[1] A.P. Abbott, D. Boothby, G. Capper, D.L. Davies, R.K. Rasheed, J. Am. Chem. Soc. 126 (2004) 9142.

[2] D.Q. Zhang, K. D. O. Vigier, S. Royer, F. Jérôme, Chem. Soc. Rev. 41 (2012) 7108.

[3] M. Francisco, A. Van den Bruinhorst, M.C. Kroon, Angew. Chem. Int. Ed. 52 (2013) 3074.

[4] E.L. Smith, A.P. Abbott, K.S. Ryder, Chem. Rev. 114 (2014) 11060.

[5] E. Durand, J. Lecomte, B. Barea, P. Villeneuve, Eur. J. Lipid Sci. Technol. 116 (2014) 16.

[6] N.V. Plechkova, K.R. Seddon, Chem. Soc. Rev. 37 (2008) 123. 
[7] M.C. Buzzeo, R.G. Evans, R.G. Compton, ChemPhysChem 5 (2004) 1106.

[8] P. Hapiot, C. Lagrost, Chem. Rev. 108 (2008) 2238.

[9] H. Olivier-Bourbigou, L. Magna, D. Morvan, Applied Cat. A 373 (2010) 1.

[10] H. Wang, G. Gurau, R.D. Rogers, Chem. Soc. Rev. 41 (2012) 1519.

[11] E.R. Cooper, C.D. Andrews, P.S. Wheatley, P.B. Webb, P. Wormald, R.E. Morris, Nature 430 (2004) 1012.

[12] P. Abbott, K.J. McKenzie, Phys. Chem. Chem. Phys. 8 (2006) 4265.

[13] C.A. Nkuku, R.J. LeSuer, J. Phys. Chem. B 111 (2007) 13271.

[14] A.P. Abbott, K. El Ttaib, G. Frisch, K.J. McKenzie, K.S. Ryder, Phys. Chem. Chem. Phys. $11(2009) 4269$.

[15] K. De Oliveira Vigier, G. Chatel, F. Jérôme, ChemCatChem. 7 (2015) 1250.

[16] D. Yang, M. Hou, H. Ning, J. Zhang, J. Ma, G. Yang, B. Han, Green Chemistry 15 (2013) $15,2261$.

[17] Y. Hou, Z. Li, S. Ren, W. Wu, Fuel Processing Technology 135 (2015) 99.

[18] L. Bahadori, N.S.A. Manan, M.H. Chakrabarti, M.A. Hashim, F.S. Mjalli, I.M. AlNashef, M.A. Hussain, C.T.J. Low, Phys. Chem. Chem. Phys. 15 (2013) 1707.

[19] L. Bahadori, M.H. Chakrabarti, N.S.A. Manan, M.A. Hashim, F.S. Mjalli, I.M. AlNashef, N. Brandon, PLoS One 10 (2015) e0144235.

[20] M.H. Chakrabarti, N. Brandon, M. Hashim, F. Mjalli, I. AlNashef, L. Bahadori, N.S.A. Manan, M.A. Hussain, V. Yufit, Int. J. Electrochem. Sci. 8 (2013) 9652.

[21] A.M. Perdizio Sakita, R. Della Noce, C.S. Fugivara, A.V. Benedetti, Anal. Chem. 89 (2017) 8296.

[22] Q. Xu, T.S. Zhao, L. Wei, C. Zhang, X.L. Zhou, Electrochim. Acta 154 (2015) 462.

[23] D. Lloyd, T. Vainikka, M. Ronkainen, K. Kontturi, Electrochim. Acta 109 (2013) 843.

[24] D. Lloyd, T. Vainikka, L. Murtomä̈i, K. Kontturi, E. Ahlberg, Electrochim. Acta 56 (2011) 4942.

[25] C. D'Agostino, R.C. Harris, A.P. Abbott, L.F. Gladdena, M.D. Mantle, Phys. Chem. Chem. Phys. 13 (2011) 21383.

[26] J.-M. Savéant, Elements of Molecular and Biomolecular Electrochemistry, WileyInterscience, 2006.

[27] A. Hayyan, F.S. Mjalli, I.M. Alnashef, T. Al-Wahaibi, Y.M. Al-Wahaibi, M.A. Hashim, Thermochim. Acta 541 (2012) 70.

[28] O.S. Hammond, D.T. Bowron, K.J. Edler, Green Chem. 18 (2016) 2736.

[29] C. D'Agostino, L.F. Gladden, M.D. Mantle, A.P. Abbott, E. I. Ahmed, A.Y.M. AlMurshedi, R.C. Harris, Phys. Chem. Chem. Phys. 17 (2015) 15297.

[30] A.W. Taylor, P. Licence, A.P.P Abbot, Phys. Chem. Chem. Phys. 13 (2011) 10147.

[31] D. Zigah, J. Ghilane, C. Lagrost, P. Hapiot, J. Phys. Chem. B 112 (2008) 14952.

[32] J. Ghilane, C. Lagrost, P. Hapiot, Anal. Chem. 79 (2007) 7383.

[33] D. Zigah, A. Wang, C. Lagrost, P. Hapiot, J. Phys. Chem. B 113 (2009) 2019. 